\title{
Impact of Recipient Vein Selection on Venous Patency and Free Flap Survival in 652 Head and Neck Reconstructions
}

\author{
Jong Woo Choi, MD, PhD, MMM ${ }^{1}$ Young Chul Kim, MD ${ }^{1}$ Dong Neok Jeon, MD ${ }^{1}$ Woo Shik Jeong, MD ${ }^{1}$ \\ Kyung S. Koh, MD, PhD ${ }^{1}$ Tae Suk Oh, MD, PhD ${ }^{1}$ Jin Sup Eom, MD, PhD ${ }^{1}$ Eun Key Kim, MD, PhD ${ }^{1}$ \\ Joon Pio Hong, MD, PhD, MMM ${ }^{1}$ Hyunsuk Peter Suh, MD, $\mathrm{PhD}^{1}$
${ }^{1}$ Department of Plastic and Reconstructive Surgery, University of Ulsan College of Medicine, Asan Medical Center, Seoul, Republic of Korea
J Reconstr Microsurg 2020;36:73-81. \\ Address for correspondence Jong Woo Choi, MD, PhD, MMM, \\ Department of Plastic and Reconstructive Surgery, University of Ulsan \\ College of Medicine, Asan Medical Center, 88, Olympic-ro 43-gil, \\ Songpa-gu, Seoul 05505, Republic of Korea \\ (e-mail: pschoi@amc.seoul.kr).
}

\begin{abstract}
Keywords

- head and neck reconstruction

- recipient vein

- flap viability

Background This study was conducted to evaluate the impact of choosing a particular recipient venous system on venous patency and flap survival in 652 head and neck free flap reconstructions.

Methods A retrospective review was performed. Patient factors investigated included: age, sex, type of flap, tumor location, history of radiation, presence of previous neck dissection, tumor stage, and any underlying disease. Data related with recipient vein including the number of anastomosis, the repair technique, the type of recipient vein, and the configuration of selected venous system were examined. The impact of patient factors and parameters related with recipient vein on the venous patency and flap survival were analyzed using bivariate and multivariate analyses.

Results Of 652 free flaps, 36 flaps (5.5\%) were re-explored due to venous congestion and 28 flaps $(77.8 \%)$ were salvaged. The overall survival rate of total free flaps was $98.8 \%$. The type of recipient venous system was found to be an insignificant factor with respect to venous congestion and flap survival in multivariate analysis. A history of radiation treatments was the only factor associated with a higher risk of venous compromise (odds ratio $[O R]=13.138, p<0.001$ ) and a lower rate of flap survival (OR $=20.182, p=0.002)$.

Conclusion The selection of recipient venous systems has no impact on venous patency and flap survival. History of radiation treatment was the only factor associated with venous congestion and flap failure. Since no single method can ensure a successful reconstructive result, selecting the optimal recipient vein should be based on individual patient factors and the surgeon's experience.
\end{abstract}

Microvascular free tissue transfer has become a reliable option for head and neck reconstruction. Overall, the success rates of microvascular reconstructions that have been reported are favorable with mostly greater than $95 \% .{ }^{1-3}$ Numerous vascular options are available due to a rich vascular network in the head and neck region, giving the reconstructive surgeons greater

received

March 25, 2019

accepted after revision

July 7, 2019

published online

August 26, 2019 flexibility and versatility. Despite the reliability of microvascular reconstruction, vascular compromise of free tissue transfer, mostly occurring as venous thrombosis, still remains problematic in up to $10 \%$ of cases. A variety of factors related with flap outcomes have been implicated in the literature, including the patient demographics and microsurgical conditions. ${ }^{1-4}$ Above

Copyright $\odot 2020$ by Thieme Medical Publishers, Inc., 333 Seventh Avenue, New York, NY 10001, USA. Tel: +1(212) 760-0888.
DOI https://doi.org/ 10.1055/s-0039-1695054. ISSN 0743-684X. 
all, choosing an optimal vein has been an essential problem, as surgeons are often faced with the challenging situations, especially in patients with frozen neck.

Traditionally, the relationship between the number of venous anastomosis and venous compromise has been an old subject of controversy. ${ }^{5-11}$ Several studies have focused on the number of anastomosis in terms of the flap venous system. The result of meta-analyses examining over 3,000 free flaps advocated dual venous anastomoses to reduce the occurrence of thromboses and overall flap failure. ${ }^{5,6,12}$ Other authors supported one venous anastomosis given that venous blood flow velocities are slower in dual venous anastomoses that may theoretically increase the risk of thromboses. ${ }^{7}$ They have reported no difference in the flap viability between single and dual venous anastomoses. ${ }^{7,8}$

However, we should also consider that the success of free tissue transfer depends not only on choosing the flap veins, but also the recipient veins. In general, the selection is divided into two types: veins from the internal jugular system and those from the subclavian venous system (SVS). Although several studies have assessed the effect of choosing a particular recipient venous system on venous patency and flap survival, sample sizes were often small to moderate, reconstructive method was limited to single flap, and detailed documentations regarding venous anastomotic configurations were lacking. Given these considerations, we retrospectively reviewed 652 cases in a single center regarding head and neck reconstructions with various free flaps to clarify the outcomes concerning the rate of venous insufficiency and flap survival based on the selection of recipient venous systems.

\section{Methods}

A retrospective review of 652 free flaps used for head and neck reconstructions following tumor ablation in 588 patients during the period of January 2005 to December 2015 was performed. This was a consecutive series, with all operations performed by a single reconstructive unit comprised of six surgeons (more than half of the reconstructive procedures were performed by one senior surgeon, J.W.C.). All patients who underwent emergent exploration due to flap compromise within 7 days after the initial operation were selected for the study.

The venous system selection was based on the location of the defect, size matching, the proximity between the flap and recipient vein, intrinsic vessel quality, favorable pedicle geometry to prevent kinking or compression, and surgeon preference. Flaps that were designed to use interpositional vein grafts, arteriovenous loops, and cephalic turnovers were excluded in this study. We preferred end-to-end anastomosis when possible, except in situations with a significant mismatch in lumen diameters (greater than 2:1) or poor vessel quality in frozen necks. All anastomoses were hand-sewn with an interrupted manner with $8-0$ or $9-0$ nylon sutures. The anastomotic coupler was not used in any cases in this study.

Pharmacologic agents were used to facilitate the patency of microanastomoses. Lipoprostaglandin E1 (Eglandin; Welfide Korea, Seoul, Korea) was administered intravenously for 7 days postoperatively. Low-molecular-weight heparin (Clexane; Sanofi-Aventis, U.S. LLC) was used until the patient began ambulation.

Flap monitoring was consistently performed by observing the surface color, turgor, capillary refill, pinprick test, and ultrasound Doppler signals (if required) every hour for the first 72 hours, every 3 hours for the next 48 hours with gradual tapering to every 8 hours until day 7 . Flaps that were buried were evaluated by ultrasound Doppler signals or by using a part of the skin paddle as a monitoring flap, especially for hypopharyngeal reconstructions. When impaired circulation was identified, the patient was immediately taken back to the operating room for re-exploration.

The primary outcome measurements were determined as follows: incidence of venous congestion, rates of successful salvage of compromised flaps, and survival rates of total free flaps. Details of patient characteristics were recorded, including age, sex, type of flap used for reconstruction, tumor location, history of radiation treatments, presence of previous neck dissections, tumor stage (T stage), and underlying conditions (hypertension, diabetes mellitus, smoking). Relationship between flap outcomes and patient factors were analyzed using Pearson's chi-squared test or Fisher's exact test. The parameters related with recipient vein features included the number of venous anastomosis, the technique for microvascular repair, the type of recipient vein, the type of recipient venous system, and detailed configuration of the selected venous system. The type of recipient venous system was categorized into three types depending on the outflow tract, flaps draining into an internal jugular venous system (IJVS), flaps draining into a SVS, and flaps draining into both IJVS and SVS. In addition, detailed configuration of selected venous system considering the number of anastomosis to each venous system were reviewed: flaps draining into a single IJVS vein, flaps draining into a single SVS vein, flaps draining into two IJVS veins, flaps draining into two SVS veins, and flaps draining into both IJVS and SVS veins. The impact of recipient vein features on the incidence of venous congestion, the salvage rates of compromised flaps, and the survival rates of total flaps was analyzed with statistical methods. For bivariate analysis, Pearson's chi-squared test was used, while Fisher's exact test was used for categorical values. Multivariate logistic regression was performed to evaluate the association of the selected recipient vein with the venous compromise and flap survival while controlling for possible confounders. Variables included: age, sex, flap type, tumor location, underlying disease, configuration of microanastomosis, and the type of selected venous system. Odds ratios (ORs) with 95\% confidence intervals were investigated and the level of significance adopted was $5 \%(\alpha=0.05)$. These analyses were performed using the SPSS software (IBM SPSS Statistics, version 21, Chicago, IL).

\section{Results}

Between January 2005 and December 2015, a total of 652 free flaps used for head and neck reconstructions in 588 patients were included. Of 588 patients, 446 (68.4\%) patients were men and 206 (31.6\%) were women (mean age, $55.71 \pm 14.81$ years; 
range, 16-98 years). Free flaps utilized in this study included the radial forearm $(n=308,47.2 \%)$, the anterolateral thigh (ALT) perforator $(n=235,36 \%)$, the fibular $(n=34,5.2 \%)$, the medial sural artery perforator (MSP) $(n=21,3.2 \%)$, and other various free flaps $(n=54,8.3 \%)$. Free flap reconstruction was performed in the oropharyngeal ( $n=378,58 \%)$, laryngopharyngeal $(n=76,11.7 \%)$, mandibular/maxillary $(n=62,9.5 \%)$, and other regions $(n=136,20.9 \%)$. Patient charts were reviewed to evaluate their radiation treatment histories, neck dissections, tumor stages, smoking status, and underlying diseases (-Table $\mathbf{1}$ ).

Of 652 free flaps, 36 flaps (5.5\%) were re-explored within 7 days from the initial surgery due to venous congestion and 28 flaps (77.8\%) were salvaged. Flap failure occurred in 8 cases (3 radial forearm, 4 ALT, and 1 MSP) with an overall flap survival rate of $98.8 \%$. A single venous anastomosis was performed in 358 flaps (54.9\%), while dual venous anastomoses were per- formed in 294 flaps (45.1\%). End-to-end anastomoses were preferentially performed in our center $(n=643,98.6 \%)$, whereas end-to-side techniques were involved in other cases (in our data, end-to-end anastomosis to the internal jugular vein [IJV] represented the employment of their side branches, while endto-side anastomosis indicated direct connection to IJV itself). For IJVS, the IJV branch ( $n=450,47.6 \%)$ was the most commonly used, followed by the superior thyroidal ( $n=161,17 \%)$, the facial $(n=102,10.8 \%)$, and the lingual $(n=3,0.3 \%)$ veins. For SVS, the external jugular vein (EJV) $(n=151,16 \%)$ was the most frequently used, followed by the superficial temporal $(n=26$, $2.7 \%$ ), the anterior jugular $(n=22,2.3 \%)$, the transverse cervical ( $n=19,2 \%$ ), and other veins. The type of selected venous system was categorized in three ways demonstrated by flaps draining into the IJVS ( $n=445,68.3 \%$ ), the SVS ( $n=94,14.4 \%$ ), and both the IJVS and the SVS ( $n=113,17.3 \%$ ). More specific classifications were described depending on the number of anastomosis

Table 1 Impact of patient characteristics on venous insufficiency and flap survival

\begin{tabular}{|c|c|c|c|c|c|c|c|c|}
\hline & & No. (\%) & $\begin{array}{l}\text { Venous } \\
\text { insufficiency } \\
\text { (\%) }\end{array}$ & $p$-Value & $\begin{array}{l}\text { Successful } \\
\text { salvage } \\
(\%)\end{array}$ & $p$-Value & $\begin{array}{l}\text { Flap } \\
\text { survival } \\
\text { (\%) }\end{array}$ & $p$-Value \\
\hline Number & & $652(100)$ & $36(5.5)$ & & $28(72.2)$ & & $\begin{array}{l}644 / 652 \\
(98.8) \\
\end{array}$ & \\
\hline \multirow[t]{3}{*}{ Age (y) } & $<50$ & $181(27.8)$ & $11(6.1)$ & 0.848 & $8(72.7)$ & 0.872 & $178(98.3)$ & 0.826 \\
\hline & $\geq 50$ and $<60$ & $189(29)$ & $9(4.8)$ & & $7(77.8)$ & & 187 (98.9) & \\
\hline & $>60$ & $282(43.3)$ & $16(5.7)$ & & $13(81.3)$ & & 279 (98.9) & \\
\hline \multirow[t]{2}{*}{ Sex } & Male & $446(68.4)$ & $25(5.6)$ & 0.89 & $20(80)$ & 0.629 & 441 (98.9) & 0.718 \\
\hline & Female & 206 (31.6) & $11(5.3)$ & & $8(72.7)$ & & $203(98.5)$ & \\
\hline \multirow{5}{*}{$\begin{array}{l}\text { Flap type of } \\
\text { reconstruction }\end{array}$} & Radial forearm & $308(47.2)$ & $21(6.8)$ & 0.275 & $18(85.7)$ & 0.32 & 305 (99) & 0.425 \\
\hline & Anterolateral thigh & $235(36)$ & $11(4.7)$ & & $7(63.6)$ & & $231(98.3)$ & \\
\hline & Fibula & $34(5.2)$ & $2(5.9)$ & & $2(100)$ & & $34(100)$ & \\
\hline & Medial sural & $21(3.2)$ & $2(9.5)$ & & $1(50)$ & & $20(95.2)$ & \\
\hline & Others & $54(8.3)$ & 0 & & & & $54(100)$ & \\
\hline \multirow{4}{*}{$\begin{array}{l}\text { Tumor } \\
\text { location }\end{array}$} & Oral/Oropharynx & $378(58)$ & $26(6.9)$ & 0.198 & $21(80.8)$ & 0.218 & $373(98.7)$ & 0.387 \\
\hline & Laryngopharynx & $76(11.7)$ & $3(3.9)$ & & $1(33.3)$ & & 74 (97.4) & \\
\hline & Mandible/Maxilla & $62(9.5)$ & $4(6.5)$ & & $3(75)$ & & $61(98.4)$ & \\
\hline & Other region & $136(20.9)$ & $3(2.2)$ & & $3(100)$ & & $136(100)$ & \\
\hline \multirow{2}{*}{$\begin{array}{l}\text { History of } \\
\text { radiation }\end{array}$} & No & $557(85.4)$ & $17(3.1)$ & $<0.001$ & $16(94.1)$ & 0.026 & $556(99.8)$ & $<0.001$ \\
\hline & Yes & $95(14.6)$ & $19(20)$ & & $12(63.2)$ & & $88(92.6)$ & \\
\hline \multirow{2}{*}{$\begin{array}{l}\text { Previous } \\
\text { neck } \\
\text { dissection }\end{array}$} & No & $544(83.4)$ & $24(4.4)$ & 0.005 & $20(83.3)$ & 0.257 & $540(99.3)$ & 0.01 \\
\hline & Yes & $108(16.6)$ & $12(11.1)$ & & $8(66.7)$ & & $104(96.3)$ & \\
\hline \multirow{2}{*}{$\begin{array}{l}\text { Tumor } \\
\text { stage }\end{array}$} & T0-T2 & $227(34.8)$ & $17(7.5)$ & 0.108 & $15(88.2)$ & 0.153 & $225(99.1)$ & 0.558 \\
\hline & T3-T4 & $426(65.2)$ & $19(4.5)$ & & $13(68.4)$ & & $419(98.6)$ & \\
\hline \multirow{2}{*}{$\begin{array}{l}\text { Diabetes } \\
\text { mellitus }\end{array}$} & No & $571(87.6)$ & $33(5.8)$ & 0.444 & $25(75.8)$ & 0.334 & $563(98.5)$ & 0.284 \\
\hline & Yes & $81(12.4)$ & $3(3.7)$ & & $3(100)$ & & 81 (12.6) & \\
\hline \multirow[t]{2}{*}{ Hypertension } & No & 467 (71.6) & $26(5.6)$ & 0.935 & $21(80.8)$ & 0.486 & 462 (98.9) & 0.565 \\
\hline & Yes & $185(28.4)$ & $10(5.4)$ & & $7(70)$ & & $182(98.4)$ & \\
\hline \multirow[t]{2}{*}{ Smoking } & No & $288(44.2)$ & $12(4.2)$ & 0.178 & $9(75)$ & 0.777 & 285 (99) & 0.702 \\
\hline & Yes & $364(55.8)$ & $24(6.6)$ & & 19 (79.2) & & 359 (98.6) & \\
\hline
\end{tabular}


in each venous system and were composed of five types including flaps draining into a single IJVS vein $(n=287,44 \%)$, a single SVS vein $(n=71,10.9 \%)$, two IJVS veins $(n=158,24.2 \%)$, two SVS veins ( $n=23,3.5 \%)$, and two IJVS and SVS veins $(n=$ 113, 17.3\%).

In bivariate analysis, there was no difference in the incidence of venous congestion, the salvage rates of compromised flaps, and the survival rates of total flaps in terms of age, sex, type of flap, tumor location, tumor stage, smoking status, and underlying disease status. However, a higher rate of venous compromise was noted in patients who previously had radiation treatments ( $20 \%$ vs. $3.1 \%, p<0.001)$ and a prior history of neck dissection $(11.1 \%$ vs. $4.4 \%, p<0.005)$. Flap survival was also significantly lower in patients who previously had radiation treatments ( $92.6 \%$ vs. $99.8 \%, p<0.001)$ and a prior history of neck dissections ( $96.3 \%$ vs. $99.3 \%, p=$ 0.01 ). Flaps with two vein anastomoses showed a higher rate of venous compromise compared with a one vein anastomosis $(7.8 \%$ vs. $3.6 \%, p=0.02)$. The end-to-side repair technique appeared to have a negative effect on flap survival, but the small number of subjects was considered a limitation of our study. The type of individual vein had no significant association with venous congestion and flap survival. For subgroup analysis of superficial and deep vein, no significant difference of venous congestion and flap survival was found in either the IJVS or SVS group. However, different rates of venous congestion were identified in terms of subcategories by the number of anastomosis in each venous system; higher thrombosis was noted when two veins of IJVS were used for anastomosis ( $n=17,10.8 \%$ ) (-Tables 1 and 2). Comparisons of venous congestion and flap survival based on parameters related with anastomotic features of recipient vein are described in -Figs. 1 and $\mathbf{2}$.

A multivariate logistic regression analysis was performed for venous compromise and flap survival associated with patient factors and parameters related to recipient vein features. A history of radiation treatments was the only factor associated with a higher risk of venous compromise $(\mathrm{OR}=13.138, p<0.001)$ and lower rates of flap survival $(\mathrm{OR}=20.182, p=0.002)$. The type of recipient venous

Table 2 Impact of parameters related with recipient vein features on venous insufficiency and flap survival

\begin{tabular}{|c|c|c|c|c|c|c|c|c|}
\hline Variables & Subvariables & No. (\%) & $\begin{array}{l}\text { Venous } \\
\text { insufficiency }\end{array}$ & $p$-Value & $\begin{array}{l}\text { Successful } \\
\text { salvage }\end{array}$ & $p$-Value & $\begin{array}{l}\text { Flap } \\
\text { survival }\end{array}$ & $p$-Value \\
\hline \multirow{2}{*}{$\begin{array}{l}\text { Number of } \\
\text { microanastomosis }\end{array}$} & One-vein & $358(54.9)$ & $13(3.6)$ & 0.02 & $9(69.2)$ & 0.354 & $354(98.9)$ & 0.779 \\
\hline & Two-vein & $294(45.1)$ & $23(7.8)$ & & $19(82.6)$ & & $290(98.6)$ & \\
\hline \multirow{3}{*}{$\begin{array}{l}\text { Microvascular } \\
\text { repair technique }\end{array}$} & End-to-end only & $643(98.6)$ & $35(5.4)$ & 0.09 & $28(80)$ & 0.058 & $636(98.9)$ & $<0.001$ \\
\hline & End-to-end plus End-to-side & $3(0.5)$ & $1(33.3)$ & & $0(0)$ & & $2(66.7)$ & \\
\hline & End-to-side only & $6(0.9)$ & 0 & & & & $6(100)$ & \\
\hline \multirow{14}{*}{$\begin{array}{l}\text { Type of } \\
\text { recipient vein }\end{array}$} & Type of recipient vein & & & 0.365 & & 0.185 & & 0.66 \\
\hline & Internal jugular venous system & & & $0.307^{\mathrm{a}}$ & & $0.153^{\mathrm{a}}$ & & $0.311^{\mathrm{a}}$ \\
\hline & Internal jugular vein branch & $450(47.6)$ & $20(4.4)$ & & $14(70)$ & & $444(98.7)$ & \\
\hline & Superior thyroidal vein & $161(17)$ & $9(5.6)$ & & $9(100)$ & & $161(100)$ & \\
\hline & Facial vein & $102(10.8)$ & $1(1)$ & & $1(100)$ & & $102(100)$ & \\
\hline & Lingual vein & $3(0.3)$ & 0 & & & & $3(100)$ & \\
\hline & Subclavian venous system & & & $0.102^{\mathrm{b}}$ & & $0.29^{\mathrm{b}}$ & & $0.673^{b}$ \\
\hline & Anterior jugular vein & $22(2.3)$ & $1(4.5)$ & & $0(0)$ & & $21(95.5)$ & \\
\hline & External jugular vein & $151(16)$ & $2(1.3)$ & & $1(50)$ & & $150(99.3)$ & \\
\hline & Transverse cervical vein & $19(2)$ & 0 & & & & $19(100)$ & \\
\hline & Retromandibular vein & $5(0.5)$ & $1(20)$ & & $1(100)$ & & $5(100)$ & \\
\hline & Occipital vein & $2(0.2)$ & 0 & & & & $2(100)$ & \\
\hline & Superficial temporal vein & $26(2.7)$ & $2(7.7)$ & & $2(100)$ & & $26(100)$ & \\
\hline & Subclavian vein branch & $5(0.5)$ & 0 & & & & $5(100)$ & \\
\hline \multirow{3}{*}{$\begin{array}{l}\text { Type of selected } \\
\text { venous system }\end{array}$} & IJVS & $445(68.3)$ & $26(5.8)$ & 0.837 & $21(80.8)$ & 0.588 & $440(98.9)$ & 0.678 \\
\hline & SVS & $94(14.4)$ & $5(5.3)$ & & $4(80)$ & & 92 (97.9) & \\
\hline & Both IJVS and SVS & $113(17.3)$ & $5(4.4)$ & & $3(60)$ & & $112(99.1)$ & \\
\hline \multirow{5}{*}{$\begin{array}{l}\text { Detailed } \\
\text { configuration } \\
\text { of selected } \\
\text { venous system }\end{array}$} & Single vein of IJVS & $287(44)$ & $9(3.1)$ & 0.019 & $6(66.7)$ & 0.263 & $284(99)$ & 0.725 \\
\hline & Single vein of SVS & $71(10.9)$ & $4(5.6)$ & & $3(75)$ & & $70(98.6)$ & \\
\hline & Two veins of IJVS/IJVS & $158(24.2)$ & $17(10.8)$ & & $15(88.2)$ & & $156(98.7)$ & \\
\hline & Two veins of SVS/SVS & $23(3.5)$ & $1(4.3)$ & & $0(0)$ & & $22(95.7)$ & \\
\hline & Two veins of SVS/IJVS & $113(17.3)$ & $5(4.4)$ & & $4(80)$ & & $112(99.1)$ & \\
\hline
\end{tabular}

Abbreviations: IJVS, internal jugular venous system; SVS, subclavian venous system.

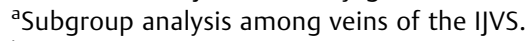

bubgroup analysis among veins of the SVS. 


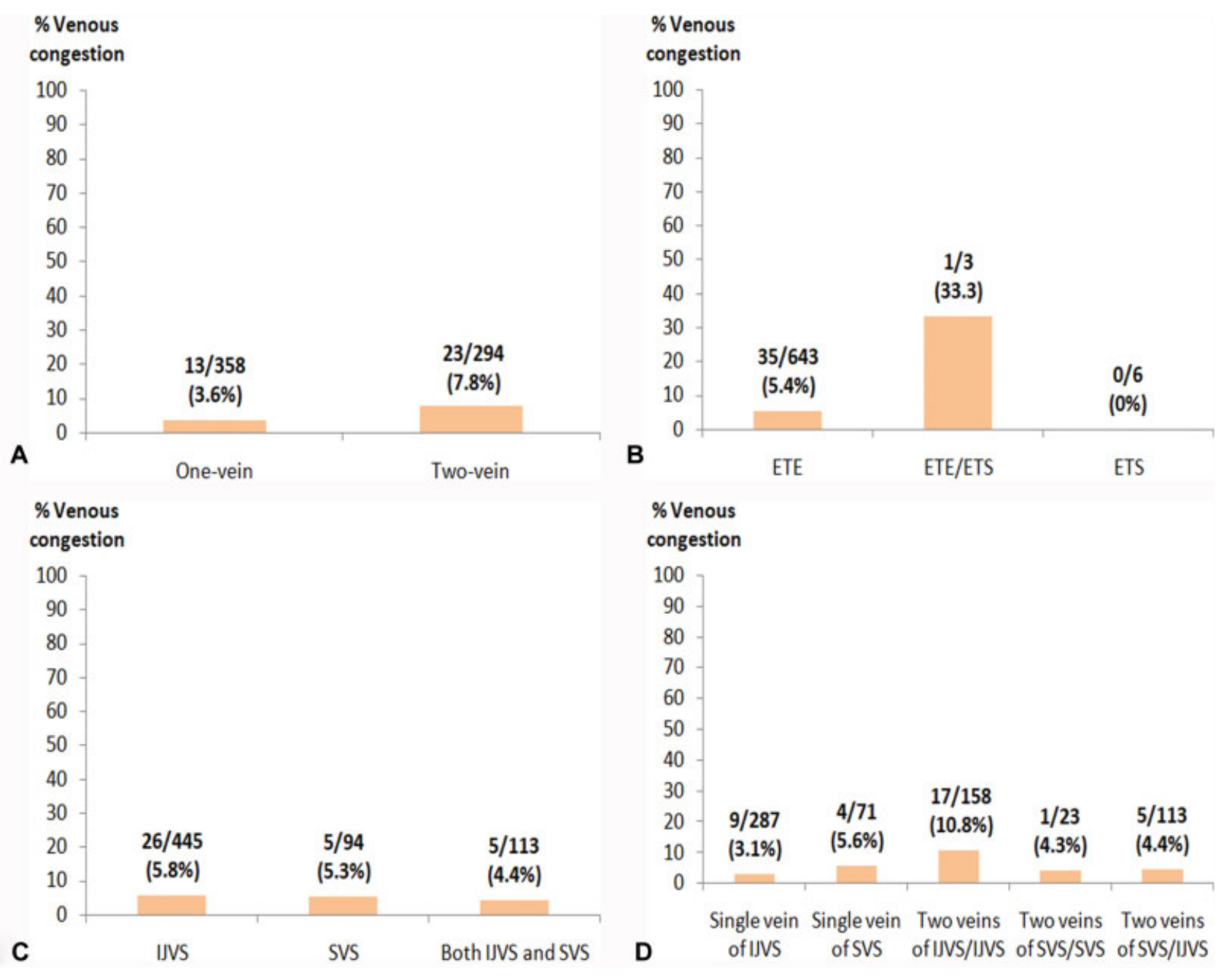

Fig. 1 Comparison of venous congestion based on parameters related with anastomotic features of recipient vein in bivariate analysis. (A) Rate of venous congestion based on number of anastomosis. (B) Rate of venous congestion based on venous anastomotic configuration. (C) Rate of venous congestion based on recipient drainage system. (D) Rate of venous congestion based on number of anastomosis and recipient drainage system. ETE, end-to-end; ETS, end-to-side; IJVS, internal jugular venous system; SVS, subclavian venous system.

system was found to be an insignificant factor with respect to venous compromise and flap survival after adjusting for flap type, tumor location, tumor stage, history of radiation treatments and neck dissection, number of anastomoses, and anastomotic configurations.

\section{Discussion}

Selection of the optimal recipient vein is crucial for the success of free tissue transfers in the head and neck region. Various options are available due to a rich vascular network in this region which makes it difficult for surgeons to choose a suitable vessel. As with other areas of the body, superficial and deep venous systems exist in the neck region. Although it is difficult to sharply define the cutoff between the superficial and deep venous systems due to anatomic variations in neck veins, ${ }^{13,14}$ we regard these vascular networks as two independent systems: the SVS and the IJVS, respectively. The SVS is characterized by drainage from the external jugular and anterior jugular veins running from the superficial or subcutaneous tissues and from the transverse cervical vein running deep or superficial to the omohyoid muscle. The IJV, which represents the deep system, is located within the carotid sheath underneath the cervical deep fascia forming multiple branches in the neck.

No consensus has yet been reached regarding whether to use the internal jugular or the SVS. ${ }^{15}$ Most authors reported that each system is equally reliable, ${ }^{4,15-18}$ while other studies supported that IJVS is the ideal recipient if technically feasible. ${ }^{19-21}$ Although debates over which system is more adequate are currently in progress (summarized in -Table 3), each system has its own advantages and disadvantages. The IJVS provides a wide range of choices with its multiple branches and has merits in facilitating venous flow by negative intrathoracic pressure during inspiration. Some studies brought up the issue of IJV thromboses, reporting up to $30 \%$ of cases in early postoperative period, and this might threaten some to use IJV especially in frozen neck. ${ }^{22-24}$ Despite this high rate of thrombosis, however, there does not seem to be a correlation between IJV thrombosis and free flap survival. In general, IJV thromboses in early postoperative period are found in radiographic imaging with higher possibility of the 


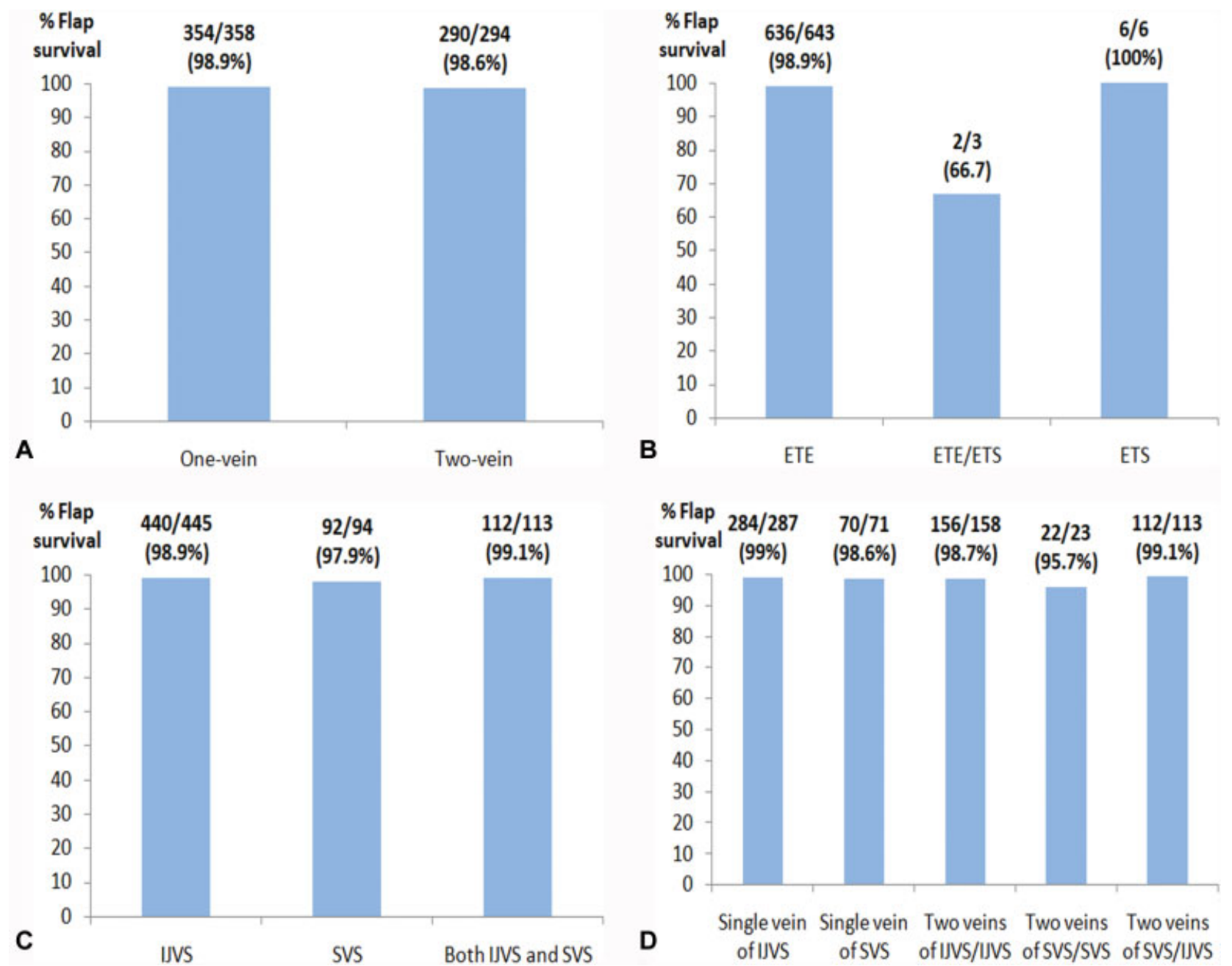

Fig. 2 Comparison of flap survival based on parameters related with anastomotic features of recipient vein in bivariate analysis. (A) Rate of flap survival based on number of anastomosis. (B) Rate of flap survival based on venous anastomotic configuration. (C) Rate of flap survival based on recipient drainage system. (D) Rate of flap survival based on number of anastomosis and recipient drainage system. ETE, end-to-end; ETS, end-toside; IJVS, internal jugular venous system; SVS, subclavian venous system.

artifact, and are mostly placed in subclinical situation in terms of flap viability.

Since the IJVS has been used as the current standard, the external and anterior jugular veins have not been routinely chosen as recipient options. Compared with the IJV, they seem to be unfavorable for recipients due to their superficial location and relatively low-flow velocity, which makes them vulnerable to external compression and neck movement and considerable intimal damage by surgical manipulation during neck dissections. ${ }^{20}$ However, it implies that the surgeon could preserve these superficial veins deliberately during neck dissection. The selection of the recipient vein can be determined preoperatively depending on the type of neck dissection. ${ }^{25}$ Yagi et al suggested that the EJV could be a better option in modified radical neck dissections while the IJV could be an optimal choice in supraomohyoid dissections. ${ }^{25}$ Moreover, given the commonly observed thrombosis of IJVs in the early postoperative period after neck dissections, ${ }^{22-24}$ the external and anterior jugular veins can be feasible options as the sole recipient vessel. ${ }^{15}$

In our series, the selection of two veins seemed to increase the risk of venous congestion and flap loss in the bivariate analysis. Specifically, using two veins from IJVS was related with increased risk of venous congestion, while other types of venous configurations were associated with a relatively lower risk. However, no relationship between the number of venous anastomosis and flap complication was found after adjusting for confounders in the multivariate analysis. And the type of selected venous system and their detailed configuration were found to be insignificant with respect to flap complication. Consequently, history of irradiation was the only factor that increased the risk of venous congestion in the multivariate analysis. In reality, given that the patients who had been irradiated were expected to have unfavorable microsurgical conditions, the surgeon is likely to perform dual anastomoses as he might not be certain of flap viability. Thus, we considered that an additional anastomosis itself did not increase the risk of venous congestion; instead, other vulnerable conditions might coexist and contribute to adverse results.

In fact, determining the recipient vein varies by the surgeon's preference and individual patient factors. To achieve optimal results, surgeons should deliberate on factors affecting the priority of the recipient vessel selection. In 


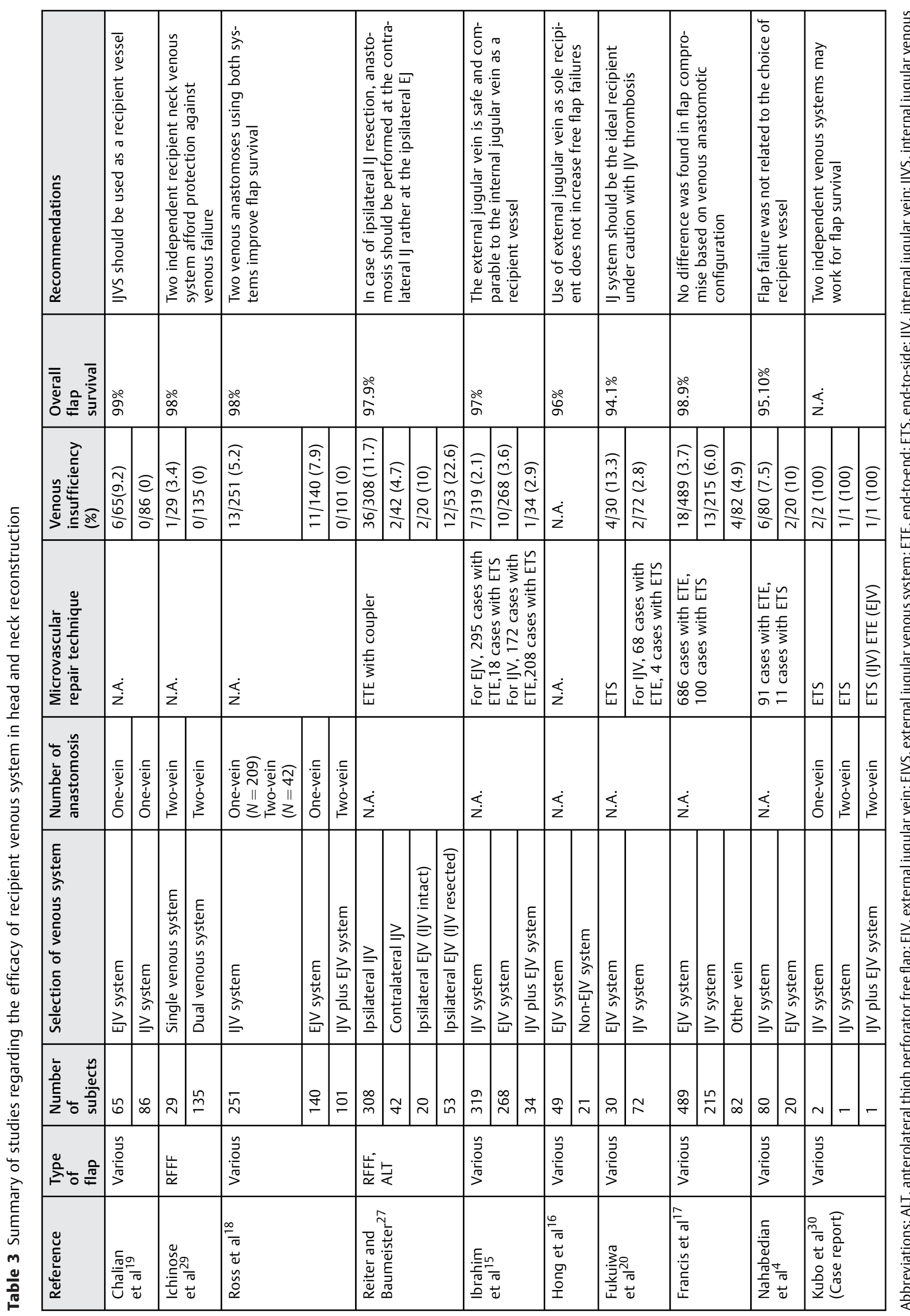

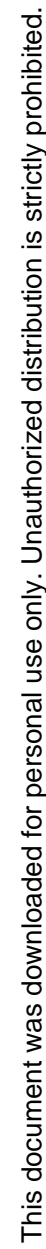


order of our preference, the IJV tributaries are explored first, considering the expected inset of flap and pedicle geometry. In majority of cases, the selection of recipient vein will not be an issue for an experienced surgeon, but circumstances arise when suitable recipient vessels are scarce due to a frozen neck. In these situations, veins draining into the SVS, most commonly the external jugular, can be used as alternative drainage routes. In our results, we found no significant differences when comparing the SVS and IJVS with respect to flap viability. The transverse cervical vein is another reliable option that can be transposed with sufficient length and tends to be less affected by irradiation and ablative procedures. Shih et al recommended the use of retrograde limb of the superficial temporal vein as an alternative option in severely vessel-depleted neck. ${ }^{26}$ They emphasized that the macro- and microvenous connection between venous system allowed direct flow through certain valves and therefore enabled the venous drainage against to the reverse flow. In case when the IJV was sacrificed during neck dissection or when it was totally occlusive, the integrity of the EJV had to be evaluated as reduced flow in the deep system may lead to elevated resistance in the superficial vein. Reiter and Baumeister reported higher risk of flap failure when anastomosis was performed to the EJV in case of ipsilateral IJV resection. ${ }^{27}$ This might attribute to the variation of EJV, as it inserts into proximal IJV instead of the subclavian vein, in around $65 \%$ of the cases. ${ }^{27}$

Possible limitations of our study include the limited number of procedures performed using the end-to-side technique, which makes it difficult to compare the effect of repair technique on flap viability. The advantages of end-to-side techniques are now widely accepted and overcome vessel mismatch problems. ${ }^{28}$ Similar successes have been noted when compared with end-to-end techniques. ${ }^{17}$ Another drawback was the exclusion of procedures performed with vein grafts and flaps connected with contralateral neck veins. This might have reduced the rate of venous problems and increased the rate of flap survival as they are highly associated with vessel depleted conditions.

\section{Conclusion}

The selection of recipient venous systems does not affect the risk of venous congestion and flap survival. A history of prior radiation therapy was the only factor associated with venous congestion and flap failure. Since no single method can ensure a successful reconstructive result, selecting the optimal recipient vein should be based on individual patient factors and the surgeon's experience.

Conflict of Interest

None declared.

\section{References}

1 Urken ML, Weinberg H, Buchbinder D, et al. Microvascular free flaps in head and neck reconstruction. Report of 200 cases and review of complications. Arch Otolaryngol Head Neck Surg 1994; 120(06):633-640
2 Suh JD, Sercarz JA, Abemayor E, et al. Analysis of outcome and complications in 400 cases of microvascular head and neck reconstruction. Arch Otolaryngol Head Neck Surg 2004;130 (08):962-966

3 Chang EI, Zhang H, Liu J, Yu P, Skoracki RJ, Hanasono MM. Analysis of risk factors for flap loss and salvage in free flap head and neck reconstruction. Head Neck 2016;38(Suppl 1): E771-E775

4 Nahabedian MY, Singh N, Deune EG, Silverman R, Tufaro AP. Recipient vessel analysis for microvascular reconstruction of the head and neck. Ann Plast Surg 2004;52(02):148-155, discussion 156-157

5 Chaput B, Vergez S, Somda S, et al. Comparison of single and double venous anastomoses in head and neck oncologic reconstruction using free flaps: a meta-analysis. Plast Reconstr Surg 2016;137(05):1583-1594

6 Riot S, Herlin C, Mojallal A, et al. A systematic review and metaanalysis of double venous anastomosis in free flaps. Plast Reconstr Surg 2015;136(06):1299-1311

7 Hanasono MM, Kocak E, Ogunleye O, Hartley CJ, Miller MJ. One versus two venous anastomoses in microvascular free flap surgery. Plast Reconstr Surg 2010;126(05):1548-1557

8 Futran ND, Stack BC Jr. Single versus dual venous drainage of the radial forearm free flap. Am J Otolaryngol 1996;17(02):112-117

9 Bartlett EL, Zavlin D, Menn ZK, Spiegel AJ. Algorithmic approach for intraoperative salvage of venous congestion in DIEP flaps. J Reconstr Microsurg 2018;34(06):404-412

10 Ehrl D, Heidekrueger PI, Heine-Geldern A, Ninkovic M, Broer PN. One versus two venous anastomoses in microvascular upper extremity reconstruction. J Reconstr Microsurg 2017;33(07): 502-508

11 Dornseifer U, Kleeberger C, Kimelman M, et al. Less Is More? impact of single venous anastomosis on the intrinsic transit time of free flaps. J Reconstr Microsurg 2017;33(02):137-142

12 Ahmadi I, Herle P, Rozen WM, Leong J. One versus two venous anastomoses in microsurgical free flaps: a meta-analysis. J Reconstr Microsurg 2014;30(06):413-418

13 Shima H, von Luedinghausen M, Ohno K, Michi K. Anatomy of microvascular anastomosis in the neck. Plast Reconstr Surg 1998; 101(01):33-41

14 Deslaugiers B, Vaysse P, Combes JM, et al. Contribution to the study of the tributaries and the termination of the external jugular vein. Surg Radiol Anat 1994;16(02):173-177

15 Ibrahim AE, Adelman DM, Parham C, et al. The external jugular vein used as recipient vessel in head and neck free flap reconstruction: outcomes compared to the internal jugular vein. J Craniofac Surg 2019;30(01):178-183

16 Hong P, Taylor SM, Trites JR, Maclean J, Hart RD. Use of the external jugular vein as the sole recipient vein in head and neck free flap reconstruction. J Otolaryngol 2006;35(06):361-365

17 Francis DO, Stern RE, Zeitler D, Izzard M, Futran ND. Analysis of free flap viability based on recipient vein selection. Head Neck 2009;31(10):1354-1359

18 Ross GL, Ang ES, Golger A, et al. Which venous system to choose for anastomosis in head and neck reconstructions? Ann Plast Surg 2008;61(04):396-398

19 Chalian AA, Anderson TD, Weinstein GS, Weber RS. Internal jugular vein versus external jugular vein anastomosis: implications for successful free tissue transfer. Head Neck 2001;23(06):475-478

20 Fukuiwa T, Nishimoto K, Hayashi T, Kurono Y. Venous thrombosis after microvascular free-tissue transfer in head and neck cancer reconstruction. Auris Nasus Larynx 2008;35(03):390-396

21 Webster RS, Chem RC. Is the recipient vein really the main concern? A cohort study of head and neck reconstruction. Microsurgery 2009;29(08):603-608

22 Wax MK, Quraishi H, Rodman S, Granke K. Internal jugular vein patency in patients undergoing microvascular reconstruction. Laryngoscope 1997;107(09):1245-1248 
23 Fisher CB, Mattox DE, Zinreich JS. Patency of the internal jugular vein after functional neck dissection. Laryngoscope 1988;98(09): 923-927

24 Brown DH, Mulholland S, Yoo JH, et al. Internal jugular vein thrombosis following modified neck dissection: implications for head and neck flap reconstruction. Head Neck 1998;20(02):169-174

25 Yagi S, Suyama Y, Fukuoka K, Takeuchi H, Kitano H. Recipient vessel selection in head and neck reconstruction based on the type of neck dissection. Yonago Acta Med 2016;59(02):159-162

26 Shih HS, Hsieh CH, Feng GM, Feng WJ, Jeng SF. An alternative option to overcome difficult venous return in head and neck free flap reconstruction. J Plast Reconstr Aesthet Surg 2013;66(09): 1243-1247
27 Reiter M, Baumeister P. Venous anastomosis in free flap reconstruction after radical neck dissection: is the external jugular vein a feasible option? Eur Arch Otorhinolaryngol 2017;274(05): 2239-2244

28 Albertengo JB, Rodriguez A, Buncke HJ, Hall EJ. A comparative study of flap survival rates in end-to-end and end-to-side microvascular anastomosis. Plast Reconstr Surg 1981;67(02):194-199

29 Ichinose A, Tahara S, Yokoo S, et al. Fail-safe drainage procedure in free radial forearm flap transfer. Journal of reconstructive microsurgery 2003;19(06):371-376

30 Kubo T, Haramoto U, Yano K, et al. Internal jugular vein occlusion in head and neck microsurgical reconstruction. Annals of plastic surgery 2002;49(05):490-494 